\title{
Population-based study of migraine in Spanish adults: relation to socio-demographic factors, lifestyle and co-morbidity with other conditions
}

\author{
César Fernández-de-las-Peñas • Valentín Hernández-Barrera • \\ Pilar Carrasco-Garrido - Cristina Alonso-Blanco - Domingo Palacios-Ceña • \\ Silvia Jiménez-Sánchez $\cdot$ Rodrigo Jiménez-García
}

Received: 26 August 2009/Accepted: 19 November 2009/Published online: 10 December 2009

(c) Springer-Verlag 2009

\begin{abstract}
The aim of this study was to estimate the prevalence of migraine in the general Spanish population and its association with socio-demographic and lifestyle factors, self-reported health status, and co-morbidity with other conditions. We analyzed data obtained from adults aged 16 years or older $(n=29,478)$ who participated in the 2006 Spanish National Health Survey (SNHS), an ongoing, home-based personal interview which examines a nation-wide representative sample of civilian non-institutionalized population residing in main family dwellings (household) of Spain. We analyzed socio-demographic characteristics (gender, age, marital status, educational level, occupational status, and monetary monthly income); self-perceived health status; lifestyle habits (smoking habit, alcohol consumption, sleep habit, physical exercise, and
\end{abstract}

\section{Fernández-de-las-Peñas}

Department of Physical Therapy, Occupational Therapy, Rehabilitation and Physical Medicine, Universidad Rey Juan Carlos, Alcorcón, Madrid, Spain

C. Fernández-de-las-Peñas

Esthesiology Laboratory, Universidad Rey Juan Carlos,

Alcorcón, Spain

V. Hernández-Barrera · P. Carrasco-Garrido ·

S. Jiménez-Sánchez · R. Jiménez-García

Preventive Medicine and Public Health Teaching and Research Unit, Department of Health Sciences, Universidad Rey Juan Carlos, Madrid, Spain

C. Alonso-Blanco $\cdot$ D. Palacios-Ceña

Department of Health Sciences II, Universidad Rey Juan Carlos,

Madrid, Spain

C. Fernández-de-las-Peñas ( $\square)$

Facultad de Ciencias de la Salud, Universidad Rey Juan Carlos, Avenida de Atenas s/n, 28922 Alcorcón, Madrid, Spain

e-mail: cesar.fernandez@urjc.es; cesarfdlp@yahoo.es obesity); and presence of other concomitant diseases. The 1-year prevalence of diagnosed migraine $(n=3,433)$ was $11.02 \%$ (95\% CI $10.55-11.51$ ). The prevalence was significantly higher among female (15.94\%) than male $(5.91 \%)$ and showed the highest value in the $31-50$ years age group $(12.11 \%)$. Migraine was more common in those of lower income (AOR 1.19, 95\% CI 1.01-1.41) and who sleep $<8 \mathrm{~h} /$ day (AOR 1.18, 95\% CI 1.04-1.33). Furthermore, worse health status (AOR 2.04, 95\% CI 1.76-2.36) and depression (AOR $1.8295 \%$ CI 1.58-2.11) were related to migraine. Finally, subjects with migraine were significantly more likely to have comorbid conditions, particularly chronic (more than 6 month of duration) neck pain (AOR 2.31, 95\% CI 1.98-2.68) and asthma (AOR 1.62, 95\% 1.27-2.05). The current Spanish population-based survey has shown that migraine is more frequent in female, between 31 and 50 years and associated to a lower income, poor sleeping, worse health status, depression and several comorbid conditions, particularly chronic neck pain and asthma.

Keywords Headache $\cdot$ Migraine $\cdot$ Co-morbidity · Population-based

\section{Introduction}

Headache is probably the most prevalent neurological pain disorder seen by medical doctors and usually experienced by almost everyone [1]. Among the different headaches, both migraine and frequent tension-type headache represent the most common forms [2,3]. Both headaches cause substantial disability for patients and their families as well as to the global society due to very high prevalence in the general population [4]. Globally, the percentage of the adult population with a headache is $47 \%$ for headache in 
general, $10 \%$ for migraine, $38 \%$ for tension-type headache, and $3 \%$ for chronic headache that lasts for more than 15 days per month [5]. In the US, the estimated total cost was $\$ 14.4$ billion for 22 million migraine sufferers [6], whereas in Europe the estimated cost was $€ 27$ billion for 41 million of patients [7].

Several studies have previously investigated the prevalence of migraine headache in the general population in different countries. Dahlöf and Linde [8] reported that the 1-year prevalence of migraine in Sweden was $13.2 \%$. Wang et al. [9] determined that the prevalence of migraine of Taiwan was $9.1 \%$. Lyngberg et al. [10] have found that the prevalence of migraine did not change significantly over 12-year period [11\% in 1989 and 15\% in 2001] in the Danish population. Strine et al. [11] also reported a prevalence of $15.1 \%$ of severe headache in a US population survey. Few epidemiological studies focused on pain disorders have been conducted in the Spanish population. Catalá et al. [12] investigated the prevalence of pain in the Spanish population and reported a prevalence of pain in the head of $20.5 \%$. Another epidemiological study conducted in Catalonia (a region of Spain) found a headache prevalence of $42 \%$ in a population of 1,964 adults [13]. Nevertheless, both studies investigated the prevalence of musculoskeletal pain. Therefore, there is not a population-based study focusing on headache conducted over the general Spanish population.

There is clearly evidence that headaches, particularly migraine, are often comorbid with other diseases, such as stroke, hypertension, diabetes, asthma, and obesity [14-16]. In addition, depression is also found in patients with headache [17]. The relationship between depression and migraine has been reported to be bidirectional as migraineurs have a fivefold increased risk of depression and patients with depression have a threefold higher risk of migraine [18]. Finally, it seems clear that headache has an adverse effect on the quality of life and health status of the patients [19, 20].

We believe that a nationwide epidemiological study about migraine in the general population and its relationship with socio-demographic factors, lifestyle habits and co-morbidity with other disorders is needed in Spain. Therefore, the aim of this study was to analyze the prevalence of migraine in the Spanish population and its association with socio-demographic factors, lifestyle habits, self-reported health status, and co-morbidity with other diseases analyzing the data from the most recent (2006) Spanish National Health Survey (SNHS).

\section{Methods}

The 2006 Spanish National Health Survey (SNHS)

The SNHS is an ongoing, home-based personal interview examining a nation-wide representative sample of civilian non-institutionalized population residing in main family dwellings (households) of Spain. The SNHS is mainly conducted by the National Statistics Institute (Instituto Nacional de Estadística, INE) under the aegis of the Spanish Ministry of Health and Consumer Affairs [21, 22]. Study subjects were selected by means of probabilistic multistage sampling, with the first-stage units being census sections, and the second-stage units, main family dwellings. More details of SNHS methodology are described elsewhere [21, 22]. In 2006, to meet the surveys' stated aim of being able to furnish estimates with a certain degree of reliability at both national and regional levels, a sample of 31,300 dwellings was selected. The data collection period started in June 2006 and finished in June 2007. Surveyors have been previously trained about basic communication skills, procedures and the used questionnaire. For purpose of the current study, we used data from a total of 29,478 subjects aged 16 year or over.

The variables included in the current study were created on the basis of a series of questions included in the questionnaires. Individuals were classified as migraine sufferers if they responded "yes" to both of the following questions: "Have you suffered from migraine over the previous 12 months?" and "Has your neurologist confirmed the diagnosis of migraine?"

We analyzed socio-demographic characteristics (i.e. gender, age, marital status, educational level, occupational status and monetary monthly income); self-perceived health status; lifestyle-related habits (smoking habits, alcohol consumption, sleep habits, physical exercise, and obesity); and presence of diagnosed concomitant chronic diseases or symptoms including high blood pressure, arthritis, chronic neck pain (neck pain with a duration of at least 6 months), low back pain, asthma, chronic bronchitis, diabetes, osteoporosis, thyroid disease, menopausal symptoms, and depression, as independent variables.

Within socio-demographic characteristics, educational level was classified into no studies ( $<6$ mandatory school years), primary (8 mandatory school years), secondary or university studies; the occupation status was reflected as home duties, students, retires, unemployed and employed; and monetary monthly income was divided as less than $€ 1,200, € 1,200-€ 1,800$ and greater than $€ 1,800$. Self-perceived health status was assessed with the following question "How did you self-perceive your health status over the previous 12 months?" Subjects described their health status as excellent, good, fair, poor or very poor. This variable was afterwards dichotomized into two: excellent/good or fair/poor/very poor self-perceived health status.

Within lifestyle habits, smoking habit differentiated between current smokers, ex-smokers or non-smokers. The alcohol consumption was measured using the question 
"Have you consumed any alcoholic drink in the last 2 weeks?" Sleep habit was divided into subjects who sleep more than $8 \mathrm{~h} /$ day and those sleeping less than $8 \mathrm{~h} /$ day. Further, subjects were also asked for: "Did you practice any physical activity, such as walking or practicing sports during your free time? Finally, the body mass index (BMI) was calculated from the self-reported body weight and height. Individuals with a $\mathrm{BMI} \geq 30$ were classified as obese.

\section{Statistical analysis}

We first estimated the prevalence of Spanish adults who could be classified as migraine sufferers and described their distribution according to the study variables and analyzed the association of these variables with the presence of migraine estimating the crude Odds Ratios (OR) with their corresponding $95 \%$ confidence intervals. Second, multivariate unconditional logistic regression models were generated, so that we could determine which of the variables covered was independently associated with suffering migraine in our population. Estimates were made using the "svy" (survey commands) functions of the STATA program, which enabled us to incorporate the sampling design and weights into all of our statistical calculations (descriptive OR, logistic regression). Statistical significance was set at two-tailed $\alpha<0.05$.

\section{Results}

Baseline demographics

From 29,478 subjects aged $\geq 16$ years included in the 2006 SNHS, a total of 3,433 answered affirmatively to both questions about migraine. Hence, the estimated prevalence of migraine sufferers among Spanish adults was $11.02 \%$ (95\% CI 10.55-11.51). The prevalence of migraine was significantly higher among female $(15.94 \%)$ than male $(5.91 \%)$ and showed the highest value in the 31-50 years age group (12.11\%). Individuals with a marital status of separated/divorced (14.66\%) showed the greatest prevalence of migraine. Furthermore, subjects with no studies were more likely to suffer from migraine $(15.15 \%)$. We also found that individuals with lower monetary income $(<1,200 €)$ were more likely to suffer from migraine (12.2\%). Finally, subjects with an occupational status of "home duties" had the highest prevalence of migraine (17.2\%) as compared to the remaining occupations. Table 1 summarizes the prevalence of migraine according to the socio-demographic variables with the crude ORs.
Additionally, the bivariate analysis revealed that individuals who self-reported a health status of fair/poor/very poor were more likely to suffer from migraine (19.23\%). Further, individuals who sleep $<8 \mathrm{~h}$ /day or those with a $\mathrm{BMI}>30$ showed a greater prevalence of migraine (12.47 and $12.99 \%$, respectively). Finally, ex-smokers were less likely to suffer from migraine $(8.96 \%)$. The prevalence of migraine with the OR according to selfperceived health status and lifestyle habits can be shown in Table 2 .

Finally, the prevalence of migraine related to the presence of concomitant self-reported chronic diseases is summarized in Table 3. All chronic diseases analyzed were significantly associated with the prevalence of migraine, except diabetes mellitus. The highest ORs were found for chronic neck pain $(4.25$, 95\% CI 3.84-4.7), depression (3.64 95\%, CI 3.27-4.05) and chronic low back pain (3.02, 95\% CI 2.73-3.34).

One-year prevalence of migraine, lifestyle habit and co-morbidity in Spanish adults

The multivariate analysis showed that the variables that were independently and significantly associated with a higher likelihood of suffering migraine among Spanish adults were female gender (OR 2.14 95\% CI 1.83-2.52), lower age (with the highest OR 1.21 for the 30-51 years group) or lower income (OR 1.19, 95\% CI 1.01-1.41) for the socio-demographic variables. Furthermore, sleep $<8 \mathrm{~h} /$ day (OR 1.18, 95\% CI 1.04-1.33) was the lifestyle habit related to migraine. In addition, a fair/poor/very poor health status was also related to the prevalence of migraine (OR 2.04, 95\% 1.76-2.36). Among the comorbid diseases, chronic neck pain (OR 2.31, 95\% CI 1.98-2.68) or asthma (OR 1.62, 95\% CI 1.27-2.05) had the highest adjusted OR. Finally, depression showed an adjusted OR of 1.82 (95\% CI 1.58-2.11). Table 4 shows the results of the multivariate analysis with the adjusted OR of those variables that were independently associated with a higher likelihood of suffering from migraine.

\section{Discussion}

Our results indicate that migraine is a major public health problem in Spain as $11.02 \%$ of our sample suffered from migraine. Further, migraine was more than twice more common in female than in men, with a peak prevalence in those aged 31-50 years. In addition, the presence of migraine was associated to a lower income, poor sleeping, worse health status, depression and other comorbid conditions, particularly chronic neck pain and asthma. 
Table 1 Prevalence of migraine by socio-demographic variables among Spanish adults, according to the 2006 Spanish National Health Survey (SNHS) $(n=29,478)$

\begin{tabular}{|c|c|c|c|c|c|}
\hline Variable & Categories & $n$ & Prevalence $(\%)$ & Crude OR & $95 \% \mathrm{CI}$ \\
\hline \multirow[t]{2}{*}{ Sex } & Male & 11,645 & 5.91 & 1 & \\
\hline & Female & 17,833 & 15.94 & 3.02 & $2.68-3.40$ \\
\hline \multirow[t]{4}{*}{ Age } & $16-30$ years & 4,536 & 8.95 & 1 & \\
\hline & $31-50$ years & 11,170 & 12.11 & 1.40 & $1.20-1.63$ \\
\hline & $51-70$ years & 8,198 & 11.73 & 1.35 & $1.15-1.59$ \\
\hline & $>70$ years & 5,574 & 10.33 & 1.17 & $0.98-1.40$ \\
\hline \multirow[t]{4}{*}{ Marital status } & Unmarried & 7,425 & 8.85 & 1 & \\
\hline & Married & 16,731 & 11.80 & 1.38 & $1.21-1.56$ \\
\hline & Widow & 3,672 & 12.73 & 1.50 & $1.26-1.79$ \\
\hline & Separated/divorced & 1,583 & 14.66 & 1.77 & $1.42-2.20$ \\
\hline \multirow[t]{4}{*}{ Educational level } & University & 4,452 & 8.83 & 1 & \\
\hline & Secondary & 10,617 & 10.19 & 1.17 & $1.00-1.37$ \\
\hline & Primary & 10,186 & 11.65 & 1.36 & $1.16-1.59$ \\
\hline & No studies & 4,086 & 15.51 & 1.90 & $1.58-2.28$ \\
\hline \multirow[t]{5}{*}{ Occupational status } & Employed & 13,624 & 9.67 & 1 & \\
\hline & Unemployed & 1,840 & 13.46 & 1.45 & $1.20-1.76$ \\
\hline & Retired & 8,040 & 10.77 & 1.12 & $0.99-1.27$ \\
\hline & Student & 1,126 & 7.90 & 0.80 & $0.60-1.06$ \\
\hline & Home duties & 4,525 & 17.16 & 1.93 & $1.70-2.19$ \\
\hline \multirow[t]{3}{*}{ Monthly income } & $>1,800 €$ & 6,630 & 9.05 & 1 & \\
\hline & $1,200-1,800 €$ & 6,551 & 11.56 & 1.31 & $1.13-1.53$ \\
\hline & $<1,200 €$ & 13,024 & 12.25 & 1.40 & $1.23-1.59$ \\
\hline \multirow[t]{2}{*}{ Migraine } & No & 26,045 & 88.98 & NA & NA \\
\hline & Yes & 3,433 & 11.02 & NA & NA \\
\hline
\end{tabular}

$N A$ not available, $C I$ confidence interval

Table 2 Prevalence of migraine according to lifestyle variables and self-perceived healthy status among Spanish adults, according to the 2006 Spanish National Health Survey (SNHS) $(n=29,478)$

\begin{tabular}{|c|c|c|c|c|c|}
\hline Variable & Categories & $n$ & Prevalence $(\%)$ & Crude OR & $95 \% \mathrm{CI}$ \\
\hline \multirow[t]{2}{*}{ Self-rated health } & Excellent/good & 18,300 & 6.89 & 1 & \\
\hline & Fair/poor/very poor & 11,178 & 19.23 & 3.21 & $2.91-3.55$ \\
\hline \multirow[t]{3}{*}{ Smoking habit } & Smoker & 7,857 & 11.23 & 1 & \\
\hline & Ex-smoker & 6,067 & 8.96 & 0.78 & $0.67-0.90$ \\
\hline & Non-smoker & 15,554 & 11.75 & 1.05 & $0.93-1.18$ \\
\hline \multirow[t]{2}{*}{ Alcohol consumption } & No & 13,948 & 14.43 & 1 & \\
\hline & Yes & 15,530 & 8.32 & 0.54 & $0.49-0.59$ \\
\hline \multirow[t]{2}{*}{ Sleep habits } & $\geq 8 \mathrm{~h} /$ night & 14,170 & 9.48 & 1 & \\
\hline & $<8 \mathrm{~h} /$ night & 15,308 & 12.47 & 1.36 & $1.23-1.50$ \\
\hline \multirow[t]{2}{*}{ Physical exercise } & Yes & 17,534 & 10.65 & 1 & \\
\hline & No & 11,944 & 11.55 & 1.09 & $0.99-1.21$ \\
\hline \multirow[t]{2}{*}{ Obesity } & $\mathrm{BMI}<30$ & 22,026 & 10.52 & 1 & \\
\hline & $\mathrm{BMI} \geq 30$ & 4,178 & 12.99 & 1.27 & $1.11-1.46$ \\
\hline
\end{tabular}

CI confidence interval 
Table 3 Prevalence of migraine according to the reported presence of associated chronic conditions among Spanish adults, according to the 2006 Spanish National Health Survey (SNHS) $(n=29,478)$

\begin{tabular}{|c|c|c|c|c|c|}
\hline Variable & Categories & $n$ & Prevalence $(\%)$ & Crude OR & $95 \%$ confidence interval \\
\hline \multirow[t]{2}{*}{ High blood pressure } & No & 22,133 & 10.13 & 1 & \\
\hline & Yes & 7,345 & 14.47 & 1.50 & $1.35-1.67$ \\
\hline \multirow[t]{2}{*}{ Arthritis } & No & 21,862 & 8.99 & 1 & \\
\hline & Yes & 7,616 & 18.89 & 2.35 & $2.13-2.60$ \\
\hline \multirow[t]{2}{*}{ Cervical pain } & No & 22,824 & 7.41 & 1 & \\
\hline & Yes & 6,654 & 25.39 & 4.25 & $3.84-4.70$ \\
\hline \multirow[t]{2}{*}{ Low back pain } & No & 22,685 & 8.28 & 1 & \\
\hline & Yes & 6,793 & 21.43 & 3.02 & $2.73-3.34$ \\
\hline \multirow[t]{2}{*}{ Asthma } & No & 27,795 & 10.52 & 1 & \\
\hline & Yes & 1,683 & 19.69 & 2.08 & $1.74-2.49$ \\
\hline \multirow[t]{2}{*}{ Chronic bronchitis } & No & 27,946 & 10.64 & 1 & \\
\hline & Yes & 1,532 & 18.58 & 1.91 & $1.59-2.31$ \\
\hline \multirow[t]{2}{*}{ Diabetes } & No & 27,322 & 10.98 & 1 & \\
\hline & Yes & 2,156 & 11.65 & 1.07 & $0.88-1.30$ \\
\hline \multirow[t]{2}{*}{ Depression } & No & 24,514 & 8.68 & 1 & \\
\hline & Yes & 4,964 & 25.71 & 3.64 & $3.27-4.05$ \\
\hline \multirow[t]{2}{*}{ Osteoporosis } & No & 27,533 & 10.38 & 1 & \\
\hline & Yes & 1,945 & 23.80 & 2.70 & $2.33-3.12$ \\
\hline \multirow[t]{2}{*}{ Thyroid diseases } & No & 28,027 & 10.59 & 1 & \\
\hline & Yes & 1,451 & 21.57 & 2.32 & $1.95-2.76$ \\
\hline \multirow[t]{2}{*}{ Menopausal symptom } & No & 16,407 & 15.12 & 1 & \\
\hline & Yes & 1,426 & 26.98 & 2.07 & $1.75-2.45$ \\
\hline
\end{tabular}

Prevalence of migraine and socio-demographic factors in Spanish adults

The prevalence of migraine obtained in this populationbased study of $15.94 \%$ for females and $6.1 \%$ for males is consistent with prior population studies conducted in Canada [23], Sweden [8], Taiwan [9], Denmark [10] and US [24]. A population-based study recently conducted in US reported a prevalence of headache of $20.5 \%$ for females and $9.2 \%$ for males [11], which is slightly superior to the current results. One possible explanation for the higher prevalence rate could be that the study by Strine et al. investigated the presence of headache experienced during the previous 3 months, whereas in the current study we analyzed the 1-year prevalence. Further, both studies related to general musculoskeletal pain symptoms conducted in Spain showed a self-reported prevalence of headache of $20.5 \%$ [12] and $42 \%$ [13]. Higher rates of prevalence in these two studies may be related to the fact that no diagnosis made by the neurologist was considered and that these two previous studies included both frequent and infrequent headaches. Schwartz et al. reported an overall 1-year prevalence of episodic headache of $38.3 \%$ [25], which would explain the higher prevalence in these two previous studies.
In the current study, we considered as migraine sufferers those individuals who answered "yes" to having migraine over the previous 12 months and diagnosed by the neurologist. Nevertheless, although neurologist usually used the International Headache Society for making the diagnosis of migraine [26], these criteria were not incorporated in the survey. Thus, although questions regarding the presence of migraine in the SNHS presume that the condition should be diagnosed by the neurologist, there remained the potential for individuals to over- or underreport their headaches. That situation may be related to the fact that $27-70 \%$ of headache sufferers have never consulted a medical doctor for their headaches [27, 28]. Further, other doctors than neurologists, e.g. general practitioners or internists, may be also able to give a migraine diagnosis. In the current population based study, we specified that migraine diagnosis should be confirmed by a neurologist since patients with suspicion of migraine are usually derived to neurologist department. Therefore, although the prevalence of migraine may be underestimated in the current study, we are still confident that individuals who are undiagnosed migraine sufferers may be similar to our diagnosed sample of subjects with migraine. Finally, although IHS criteria were not used implicated in 
Table 4 Variables independently and significantly associated with a higher likelihood of suffering migraine among Spanish adults, according to the 2006 Spanish National Health Survey (SNHS)

\begin{tabular}{|c|c|c|c|}
\hline Variable & Categories & $\begin{array}{l}\text { Adjusted } \\
\text { OR }\end{array}$ & $\begin{array}{l}95 \% \text { confidence } \\
\text { interval }\end{array}$ \\
\hline \multirow[t]{2}{*}{ Sex } & Male & 1 & \\
\hline & Female & 2.14 & $1.83-2.52$ \\
\hline \multirow[t]{4}{*}{ Age } & $16-30$ years & 1 & \\
\hline & $31-50$ years & 1.22 & $1.01-1.41$ \\
\hline & $51-70$ years & 0.61 & $0.50-0.74$ \\
\hline & $>70$ years & 0.41 & $0.32-0.51$ \\
\hline \multirow[t]{3}{*}{ Monthly income } & $>1,800 €$ & 1 & \\
\hline & $1,200-1,800 €$ & 1.09 & $0.91-1.29$ \\
\hline & $<1,200 €$ & 1.19 & $1.01-1.41$ \\
\hline \multirow[t]{2}{*}{ Self-rated health } & Excellent/good & 1 & \\
\hline & Fair/poor/very poor & 2.04 & $1.76-2.36$ \\
\hline \multirow[t]{2}{*}{ Sleep habits } & $\geq 8$ hours/night & 1 & \\
\hline & $<8$ hours/night & 1.18 & $1.04-1.33$ \\
\hline \multirow[t]{2}{*}{ High blood pressure } & No & 1 & \\
\hline & Yes & 1.24 & $1.05-1.47$ \\
\hline \multirow[t]{2}{*}{ Cervical pain } & No & 1 & \\
\hline & Yes & 2.31 & $1.98-2.68$ \\
\hline \multirow[t]{2}{*}{ Low back pain } & No & 1 & \\
\hline & Yes & 1.33 & $1.14-1.55$ \\
\hline \multirow[t]{2}{*}{ Asthma } & No & 1 & \\
\hline & Yes & 1.62 & $1.27-2.05$ \\
\hline \multirow[t]{2}{*}{ Depression } & No & 1 & \\
\hline & Yes & 1.82 & $1.58-2.11$ \\
\hline
\end{tabular}

our study, our findings agree with previous population-based studies on the epidemiology of migraine [8-10, 23, 24].

Our findings are also consistent with previous published studies in that migraine has a peak prevalence between 25 and 50 years $[9,11,23,24]$. The prevalence of migraine was also highest in those of lower income, consistent with population-based studies conducted in Canada [23] and US [29]. Finally, poor sleeping ( $<8 \mathrm{~h} /$ day) was also associated to the presence of migraine in agreement with the study conducted by Strine et al. [11]. This association has been supported by recent studies reporting that sleep impairment is not only one of the most common symptoms of migraine but is also the most common trigger [30, 31].

Presence of migraine, self-reported health status, and comorbid conditions

The current population-based study found that Spanish adults with migraine reported worse health status, depression and a myriad of other comorbid conditions. It seems clear that migraine is associated with poor health quality of life $[32,33]$. Previous studies investigating quality of life and/or health status of patients with migraine were conducted over clinic populations, which may difficult the extrapolation of the results to the general population. Nevertheless, several population-based studies, including the current one, have also confirmed that subjects suffering from migraine are more likely to self-perceive a worse health status than those without headache.

In this study, we also showed that individuals with migraine reported a greater diagnosis of depression. The relationship between depression and headaches has been reported to be bidirectional $[17,18]$. Nevertheless, when population-based data are adjusted for coexisting tensiontype headache it was clear that tension-type headache, but not migraine was the main predictor for depression [10]. In the current study, our migraine sufferers answered positively to the presence of diagnosed migraine. It is possible that individuals with non-migrainous headache suffered from frequent tension-type headache, although we cannot confirm this. In future population-based studies, and in our work as clinicians, it would be important to identify comorbid disorders including coexisting headache diagnoses as both the neurobiology, management and outcome of headache seems to be closely correlated to co-morbidity [10].

In addition, several studies have demonstrated that migraine is often comorbid with other conditions, such as depression, asthma, diabetes, hypertension or obesity [14, 17]. We found that migraine was associated with high blood pressure, neck and low back pain, and asthma. Among these conditions, chronic neck pain and asthma showed the highest adjusted OR. In such a way, individuals with migraine were approximately 2.3 times more likely to report neck pain symptoms than those without headache. This was expected as there is evidence showing a pathophysiological connection between neck and migraine [34]. Further, individuals reporting migraine were approximately 1.6 times more likely to have asthma than those without headache, which agrees with the results previously found by Aamodt et al. [35] and Davey et al. [36]. Several theories are plausible for explaining the co-morbidity of these conditions with migraine, but reviewing them are beyond the scope of this study. Nevertheless, clinicians should be aware of these comorbid conditions to improve the management of individuals with migraine.

\section{Limitations}

Although some strengths of this study were a large sample size and a randomly population, there are a number of possible limitations. First, the validity of the questions included in the SNHS to classify subjects as migraine sufferers has not been evaluated. Several published studies carried out in Spanish subjects that used telephone surveys 
and specific questionnaire about frequency and localization of pain found results which are similar to ours with regard to the population characteristics, and argue in favor of the validity of the method used and the sample's representativeness $[12,13]$. Population-based surveys have been previously employed by others in countries as US [11] or Canada [23] to estimate the prevalence of migraine/headache and factors associated to this disease. In any case, we agree with Lipton et al. who found that to estimate the prevalence of migraine it is required that individuals reporting the disease had been also diagnosed by a neurologist, although the real prevalence may be underestimated [37].

Second, all information obtained within the interviews may be subject to recall errors or a tendency of subjects to give socially desirable responses within interviews, particularly regarding lifestyle habits [38]. Third, information on relevant variables such as pharmacological treatment, duration or severity of headache is not currently collected by the Spanish National Health Survey which may act as confounding factors in some associations.

\section{Conclusions}

The current population-based survey showed a 1-year prevalence of migraine of $11.02 \%$ in Spanish adults. Migraine was more frequent in female, between 31 and 50 years of age and associated to lower income, poor sleeping, worse health status, depression and other comorbid conditions, particularly chronic neck pain and asthma. Clinicians should be aware of comorbid conditions to improve the management of subjects with migraine.

Conflict of interest None.

\section{References}

1. Bendtsen L, Jensen R (2009) Epidemiology of tension-type headache, migraine and cervicogenic headache. In: Fernández de las Peñas C, Arendt-Nielsen L, Gerwin R (eds) Tension type and cervicogenic headache: patho-physiology, diagnosis and treatment. Jones \& Bartlett Publishers, Baltimore, pp 7-13

2. Rasmussen BK, Jensen R, Schroll M, Olesen J (1991) Epidemiology of headache in a general population: a prevalence study. J Clin Epidemiol 44:1147-1157

3. Bendtsen L, Jensen R (2006) Tension type headache: the most common, but also the most neglected headache disorder. Curr Opin Neurol 19:305-309

4. Stovner L, Hagen K, Jensen R, Katsarava Z, Lipton R, Scher A, Steiner T, Zwart JA (2007) The global burden of headache: a documentation of headache prevalence and disability worldwide. Cephalalgia 27:193-210

5. Jensen R, Stovner LJ (2008) Epidemiology and co-morbidity of headache. Lancet Neurol 7:354-361

6. Hu XH, Markson LE, Lipton RB, Stewart WF, Berger ML (1999) Burden of migraine in the United States: disability and economic costs. Arch Intern Med 159:813-818
7. Andlin-Sobocki P, Jonsson B, Wittchen HU, Olesen J (2005) Cost of disorders of the brain in Europe. Eur J Neurol 12(Suppl 1): $1-27$

8. Dahlöf C, Linde M (2001) One-year prevalence of migraine in Sweden: a population-based study in adults. Cephalalgia 21: 664-671

9. Wang SJ, Fuh JL, Young YHm Lu SR, Chia BC (2000) Prevalence of migraine in Taipei, Taiwan: a population-based survery. Cephalalgia 20:566-572

10. Lyngberg AC, Rasmussen BK, Jorgensen T, Jensen R (2005) Has the prevalence of migraine and tension-type headache changed over a 12-year period? A Danish population survey. Eur J Neurol 20:243-249

11. Strine TW, Chapman DP, Balluz LS (2006) Population-based US study of severe headaches in adults: psychological distress and co-morbidities. Headache 46:223-232

12. Catalá E, Reig E, Artés M, Aliaga L, López JS, Segú JL (2002) Prevalence of pain in the Spanish population: a telephone survey in 5000 homes. Eur J Pain 6:133-140

13. Bassols A, Bosch F, Campillo M, Canellas M, Baños J (1999) A epidemiological comparison of pain complaints in the general population of Catalonia [Spain]. Pain 83:9-16

14. Scher AI, Bigal ME, Lipton RB (2005) Comorbidity of migraine. Curr Opin Neurol 18:305-310

15. Aamodt AH, Stovner LJ, Midthjell K, Hagen K, Zwart JA (2007) Headache prevalence related to diabetes mellitus: the HeadHUNT study. Eur J Neurol 14:738-744

16. Kurth T, Gaziano JM, Cook NR et al (2007) Migraine and risk of cardiovascular disease in men. Arch Intern Med 167:795-801

17. Tietjen GE, Herial NA, Hardgrove J, Utley C, White L (2007) Migraine co-morbidity constellations. Headache 47:857-865

18. Breslau N, Lipton RB, Stewart WF, Schultz LR, Welch K (2003) Co-morbidity of migraine and depression: investigating potential etiology and prognosis. Neurology 60:1308-1312

19. Melitiche DM, Lofland JH, Young WB (2001) Quality of life differences between patients with episodic and transformed migraine. Headache 41:573-578

20. Wang SJ, Fuh JL, Lu SR, Juang KD (2001) Quality of life differs among headache diagnoses: analysis of SF-36 survey in 901 headache patients. Pain 89:285-292

21. Instituto Nacional de Estadística (INE) Encuesta Nacional de Salud de España (2006) Spanish National Health Survey 2006. Accessed in 11 January 2009. Available from: http://www.msc. es/estadEstudios/estadisticas/encuestaNacional/encuesta2006. htm

22. Instituto Nacional de Estadística (INE), Encuesta Nacional de Salud de España (2006) Spanish National Health Survey 2006: Details on the evaluation of non respondents. Accessed in 11 January 2009. Available from: http://www.msc.es/estadEstudios/ estadisticas/encuestaNacional/encuestaNac2006/evaluacionFalta Resp.pdf

23. Jette N, Patten S, Williams J, Becker W, Wiebe S (2008) Comorbidity of migraine and psychiatric disorders-a national population-based study. Headache 48:501-516

24. Lipton RB, Scher AI, Kolodner K, Liberman J, Steiner TJ, Stewart WF (2002) Migraine in the United States: epidemiology and patterns of health care use. Neurology 58:885-894

25. Schwartz BS, Stewart WF, Simon D, Lipton RB (1998) Epidemiology of tension type headache. JAMA 279:381-383

26. IHS Headache Classification Subcommittee of the International Headache Society (2004) The international classification of headache disorders, 2nd edn. Cephalalgia 24(suppl 1):9-160

27. Lucas C, Geraud G, Valade D, Chautard MH, Lanteri-Minet M (2006) Recognition and therapeutic management of migraine in 2004 in France: results of FRAMIG 3, a French nationwide population-based survey. Headache 46:715-725 
28. Cooke L, Becker W (2006) Migraine prevalence, disability, and treatment: Canadian women and migraine survey. Can J Neurol Sci 33(Supp1):S27-S28

29. Stewart WF, Lipton RB, Celentano DD, Reed ML (1992) Prevalence of migraine headache in the United States: relation to age, income, race, and other socio-demographic factors. JAMA 267:64-69

30. Takeshima T, Ishizaki K, Fukuhara Y et al (2004) Populationbased door-to-door survey of migraine in Japan: The Daisen study. Headache 44:8-19

31. Boardman HF, Thomas E, Millson DS, Croft PR (2005) Psychological, sleep, lifestyle, and comorbid associations with headache. Headache 45:657-669

32. Ruiz deVelasco I, Gonzalez N, Etxeberria Y, Garcia-Monco JC (2003) Quality of life in migraine patients: a qualitative study. Cephalalgia 23:892-900

33. Terwindt GM, Ferrari MD, Tijhuis M, Groenen SM, Picavet H, Launer L (2000) The impact of migraine on quality of life in the general population: The GEM study. Neurology 55:624-629
34. Bartsch T (2005) Migraine and the neck: New insights from basic data. Curr Pain Head Rep 9:191-196

35. Aamodt AH, Stovner LJ, Langhammer A, Hagen K, Zwart JA (2007) Is headache related to asthma, hay fever, and chronic bronchitis? The Head-HUNT Study. Headache 47:204-212

36. Davey G, Sedgwick P, Maier W, Visick G, Strachan DP, Anderson HR (2002) Association between migraine and asthma: matched case-control study. Br J Gen Pract 52:723-727

37. Lipton RB, Stewart WF, Celentano DD, Reed ML (1992) Undiagnosed migraine headaches: a comparison of symptombased and reported physician diagnosis. Arch Intern Med 152:1273-1278

38. Basterra-Gortari FJ, Bes-Rastrollo M, Forga L, Martínez JA, Martínez-González MA (2007) Validity of self-reported body mass index in the National Health Survey [Spanish]. Sist Sanit Navar 30:373-381 